\title{
Minimal cross-subsidies approach for loss allocation in distribution networks with open access
}

DOI:

10.1109/PES.2007.385804

Link to publication record in Manchester Research Explorer

\section{Citation for published version (APA):}

Ochoa, L. F., Oliveira, M. E., \& Padilha-Feltrin, A. (2007). Minimal cross-subsidies approach for loss allocation in distribution networks with open access. In 2007 IEEE Power Engineering Society General Meeting, PES/

https://doi.org/10.1109/PES.2007.385804

\section{Published in:}

2007 IEEE Power Engineering Society General Meeting, PES|

\section{Citing this paper}

Please note that where the full-text provided on Manchester Research Explorer is the Author Accepted Manuscript or Proof version this may differ from the final Published version. If citing, it is advised that you check and use the publisher's definitive version.

\section{General rights}

Copyright and moral rights for the publications made accessible in the Research Explorer are retained by the authors and/or other copyright owners and it is a condition of accessing publications that users recognise and abide by the legal requirements associated with these rights.

\section{Takedown policy}

If you believe that this document breaches copyright please refer to the University of Manchester's Takedown Procedures [http://man.ac.uk/04Y6Bo] or contact uml.scholarlycommunications@manchester.ac.uk providing relevant details, so we can investigate your claim.

\section{OPEN ACCESS}




\title{
Minimal Cross-Subsidies Approach for Loss Allocation in Distribution Networks with Open Access
}

\author{
L. F. Ochoa, Member, IEEE, M. E. Oliveira, Student Member, IEEE, \\ and A. Padilha-Feltrin, Senior Member, IEEE
}

\begin{abstract}
Open access philosophy applied by regulatory agencies may lead to a scenario where captive consumers will solely face the responsibility on distribution network's losses even with Independent Energy Producers (also known as Distributed Generation) and Independent Energy Consumers connected to the system. This work proposes the utilization of a loss allocation method in distribution systems where open access is allowed, in which cross-subsidies, that appear due to the influence the generators have over the system losses, are minimized. Thus, guaranteeing to some extent the efficiency and transparency of the economic signals of the market. Results obtained through the Zbus loss allocation method adapted for distribution networks are processed in such a way that the corresponding allocation to the generation buses is divided among the consumer buses, while still considering consumers spatial characteristics.
\end{abstract}

Index Terms-- Loss allocation, distribution systems, open access, distributed generation.

\section{INTRODUCTION}

$\mathrm{T}$ HE search for economic efficiency in transmission systems, which started after the deregulation of the electric sector in various countries, has propelled the appearance of a number of methods for loss allocation. These methods, in general, try: to reflect power or current injections at each bus; to reflect network topology; to be simple for understanding and implementation; to provide effective incentives or otherwise to generation or load buses; and, to be consistent with the power flow solution. Nonetheless, specialized literature agrees that there are difficulties when adopting a loss allocation method since there will always be a certain degree of arbitrariness due to the non-linear characteristic of losses.

As for distribution systems, currently most electric utilities do not have a policy where technical losses are allocated among the participant agents according to a strictly technical criterion, as it usually occurs with transmission networks.

The first author is grateful for the financial support given by FEPISA (Ilha Solteira - SP, Brazil). The second author is grateful for the financial support given by Fundação de Amparo à Pesquisa do Estado de São Paulo (FAPESP) Process No. 04/04400-4.

L. F. Ochoa M. E. Oliveira and A. Padilha-Feltrin are with the Department of Electrical Engineering, UNESP - Ilha Solteira, SP - Brazil

e-mail: luis_ochoa@ieee.org, escobar.oliveira@ieee.org, padilha@dee.feis.unesp.br.
Commonly, the billing due to the consumed energy by each client includes a share of the system's losses. In Brazil, for instance, this share is calculated according to the voltage level of the captive consumer, independently of its location and size relative to the other captive consumers at the same voltage level. Consequently, this share is not the reflection of a fair allocation since it is solely based on the energy cost calculation.

Moreover, given the open access philosophy applied by regulatory agencies, Independent Energy Producers (IEPs) also know as Distributed Generation (DG)- and Independent Energy Consumers (IECs) are allowed to connect to the distribution network and negotiate energy contracts with agents outside the host distribution network. In this way, a scenario where open access is used, distribution network's losses, result of the presence of all agents, i.e., IEPs, IECs and captive consumers, will solely be responsibility of the latter. This may be considered unfair given that IEPs and IECs power flows are indeed using the host distribution network, affecting the total power losses.

Application of loss allocation methods found in the literature would result, in many cases, in negative loss allocation for generation units due to their contribution diminishing network's total losses. Such a negative allocation may create high cross-subsidies values affecting consequently the efficiency and transparency of the economic signals of the market [1], [2].

Considering the regulating framework above described, in this work it is proposed the utilization of a loss allocation method adapted for distribution systems with open access. Cross-subsidies are to be minimized by re-allocating generators' loss allocation to the consumers (IECs and captive consumers).

The paper is set out as follows: section 2 describes the Zbus loss allocation method adapted for distribution networks [3], as well as the method for the loss re-allocation based on Zhao et al. [4]. A small example is solved for showing the details of the calculation process. In section 3 the analysis for the IEEE-34 test feeder considering the insertion of generation units is performed. Results are presented and discussed. Conclusions are drawn in section 4. 


\section{Accepted Paper}

\section{LOSS ALLOCATION IN DISTRIBUTION NETWORKS}

Loss allocation method Zbus [5], that is to be applied in distribution systems, was selected mainly due to the use of exact network equations, thus not requiring approximations, and to be of easy implementation. The process used to detach the generation units from the final calculation of loss allocation, i.e., to distribute the losses allocated in the generation nodes into the consumer nodes, is based on [4].

\section{A. The Zbus method for Distribution Networks}

Proposed in 2001 by Conejo et al. [5], the Zbus loss allocation method is utilized in transmission systems. It firstly considers the network's admittance matrix $Y=G+j B$, typically large, sparse and non-singular. Knowing the complex values of the nodal current injections $I$ and the nodal voltages $V$, system's real power losses may be expressed in terms of $Y$ and $V$, or $Z$ and $I$; where $Z=Y^{-1}=R+j X$ is the network's impedance matrix.

Therefore, total power losses $L$ are systematically distributed among the $n$ nodes found in the system:

$$
L=\sum_{i=1}^{n} L_{i}
$$

where $L$ is computed in the following manner:

$$
L=\operatorname{Re}\left\{\sum_{k=1}^{n} I_{k}^{*}\left(\sum_{j=1}^{n} Z_{k j} I_{j}\right)\right\}
$$

Impedance $Z_{k j}$ may be decoupled into its resistance and reactance, nonetheless, the summation related to the reactance represents the aggregation of the power flows of those nodes connected through matrix $Z$ to node $k$, which results in zero. Consequently, (2) can be re-written as:

$$
L=\operatorname{Re}\left\{\sum_{k=1}^{n} I_{k}^{*}\left(\sum_{j=1}^{n} R_{k j} I_{j}\right)\right\}
$$

Finally, total losses can be decoupled in $n$ fractions of losses that represent the losses attributed to each node:

$$
L_{i}=\operatorname{Re}\left\{I_{i}^{*}\left(\sum_{j=1}^{n} R_{k j} I_{j}\right)\right\}
$$

At this point, two particularities of distribution systems should be considered: network's admittance matrix $Y$ is singular since the capacitive effect of the lines is not taken into account; and, the loss allocation must be performed among the agents that utilize the network. Thus, with the aim of eliminating matrix $Y^{\prime} \mathrm{s}$ singularity and maintaining coherence with the loss allocation results, it is necessary to exclude the participation of the reference node, i.e., the substation. It is important to remark that this consideration does not affect neither the fair allocation nor the value of the system's total losses [3].

\section{B. Loss Re-allocation}

Proposed in 2004 by Zhao et al. [4], the Improved Zbus method was presented to be used in transmission networks. In distribution systems, total power losses of a network with
IEPs can be divided into two parts: one caused by the generation $\left(L_{G}\right)$ and other corresponding to the consumers $\left(L_{C}\right)$. Considering that the economic equilibrium of the network must be kept, the extra cost created by the loss allocation should be subtracted by the levy of the generation and increased in the cost of the consumers. Assuming a scenario where all generators are paid based on a single price $p_{G}$ and all consumers have to pay for the energy supply based on a single price $p_{C}$, the total payment for the generators $(\alpha)$ would be calculated as follows:

$$
\alpha=p_{G} \cdot \sum_{k=1}^{N_{G}}\left(P_{G k}-L_{G k}\right)
$$

and the total billing $(\beta)$ of the consumers would be:

$$
\beta=p_{C} \cdot \sum_{i=1}^{N_{C}}\left(P_{C i}+L_{C i}\right)
$$

whereas $N_{G}$ and $N_{C}$ are the total number of generation units and consumers, respectively.

Due to the equilibrium among economic transactions, i.e. $\alpha$ is equal to $\beta$, it is obtained:

$$
p_{G}=\frac{p_{C} \cdot \sum_{i=1}^{N_{C}}\left(P_{C i}+L_{C i}\right)}{\sum_{k=1}^{N_{G}}\left(P_{G k}-L_{G k}\right)}
$$

Thus, the total cost produced by the losses allocated to generation units $\left(\alpha_{L}\right)$ :

$$
\alpha_{L}=p_{G} \cdot \sum_{k=1}^{N_{G}} L_{G k}
$$

can be re-written by using (7):

$$
\alpha_{L}=p_{C} \cdot \frac{\sum_{i=1}^{N_{C}}\left(P_{C i}+L_{C k}\right)}{\left(\sum_{k=1}^{N_{G}} P_{G i} / \sum_{k=1}^{N_{G}} L_{G k}\right)-1}
$$

The expression that is multiplied by the price $p_{C}$ represents the total losses allocated to the generators. This representation allows distributing that value to each consumer $j$ present in the network. Thus, the corresponding new loss allocation is computed by the following expression:

$$
L_{C j \text { novo }}=L_{C j}+\frac{P_{C j}+L_{C j}}{\left(\sum_{k=1}^{N_{G}} P_{G k} / \sum_{k=1}^{N_{G}} L_{G k}\right)-1}
$$

It is important to highlight that this process requires maintaining coherence among generation, demand and losses; therefore, the substation must be included as being a "generator" whose injected power is obtained through the power flow solution. Moreover, given that in the loss allocation calculation the reference node was eliminated for the network's admittance matrix, the corresponding loss allocation is equal to zero.

This methodology considers as a generation node that whose injected power exceeds its demand. Analogically, a consumer node will present demand larger than the injected 
power in case there is a generation unit installed on it.

\section{Application Example}

Fig. 1 shows a simple single-line radial feeder with the respective load (power factor equal to unity) and voltage data. Each line section has a impedance equal to $1.1993+j 0.877 \Omega$.

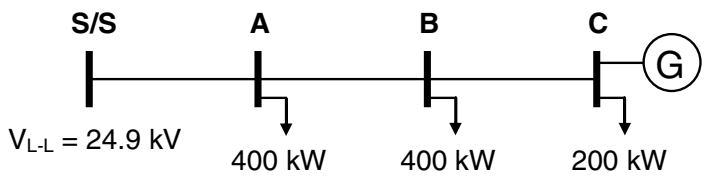

Fig. 1. Single-line radial feeder.

Varying the power generation output (unity power factor) of the generation unit inserted at node $\mathrm{C}$, the Zbus loss allocation method adopted for distribution systems (substation is not taken into account) was applied. Results are presented in Table I. Fig. 2 presents the behavior of the losses allocated at each power generation scenario.

TABLE I

RESULTS OF THE ADAPTED ZBUS LOSS ALLOCATION FOR FEEDER IN FIG. 1

\begin{tabular}{c|c|c|c|c}
\cline { 2 - 5 } & \multicolumn{4}{|c}{ Losses (kW) } \\
\hline $\begin{array}{c}\text { Power } \\
\text { Generation } \\
\text { Output (kW) }\end{array}$ & A & B & C & Total \\
\hline 0 & 2.3538 & 3.7815 & 2.1300 & 8.2652 \\
\hline 300 & 1.6395 & 2.3470 & -0.5278 & 3.4587 \\
\hline 600 & 0.9350 & 0.9371 & -0.0065 & 1.8656 \\
\hline 800 & 0.4707 & 0.0108 & 2.0585 & 2.5400 \\
\hline 1000 & 0.0106 & -0.9053 & 5.4660 & 4.5713 \\
\hline
\end{tabular}

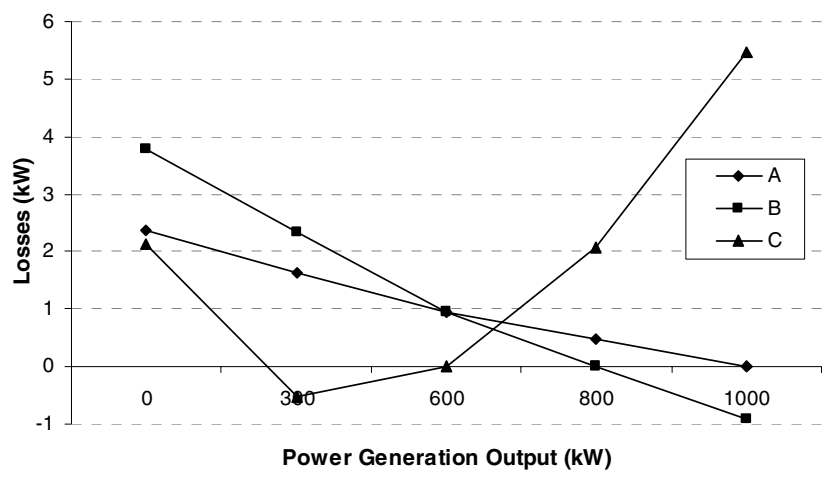

Fig. 2. Results of the Zbus loss allocation for the feeder in Fig. 1.

As expected, it is verified that the generator diminishes significantly the total losses in the feeder. However, this occurs until a certain scenario where this value starts to rise. When the generation unit helps effectively to decrease losses (power output of 300 and $600 \mathrm{~kW}$ ), negative losses (crosssubsidies) are allocated to node C. A power generation output of $800 \mathrm{~kW}$ produces more power flows towards the substation (counter flows or reverse flows), leading to positive loss allocation for node C. As for $1000 \mathrm{~kW}$ power generation, the Zbus method is consistent showing that the main agent in the total losses is node $\mathrm{C}$. In this case, negative losses are allocated to node $\mathrm{B}$, producing again cross-subsidies.
In Fig. 2, it is visible that from a given power generation output (in this case, $300 \mathrm{~kW}$ ) the losses allocated to node $\mathrm{C}$ exhibit an increasing trend. As for the load nodes, this trend is always decreasing.

Equation (11) shows the numeric calculation required to obtain the new loss allocation for node A considering a 300 $\mathrm{kW}$ power generation output. It should be taken into account that: the value of $703.4587 \mathrm{~kW}$ corresponds to the power injection from the substation; load at node $\mathrm{C}(200 \mathrm{~kW})$ is subtracted from the power generation; and, loss allocation at the substation is equal to zero.

$$
\begin{aligned}
& L_{\text {Anew }}=1.6395+\frac{400+1.6395}{\frac{703.4587+300-200}{-0.5278}-1} \\
& L_{\text {Anew }}=1.3758
\end{aligned}
$$

The results corresponding to the re-allocation of those losses obtained in Table I, are presented in Table II. The values of the total losses coincide with that computed by the power flow analysis. Also, there are no losses allocated to the generation node. Fig. 3 shows the curves produced by the new loss allocation values. It can be noticed that both load nodes, $\mathrm{A}$ and $\mathrm{B}$, present trends similar to that presented by the generation node (C) in Fig. 2.

TABLE II

RESULTS OF THE LOSS RE-ALLOCATION FOR THE FEEDER IN FIG. 1

\begin{tabular}{c|c|c|c|}
\cline { 2 - 4 } & \multicolumn{3}{|c}{ Losses (kW) } \\
\hline $\begin{array}{c}\text { Power } \\
\text { Generation } \\
\text { Output (kW) }\end{array}$ & A & B & Total \\
\hline 300 & 1.3758 & 2.0828 & 3.4587 \\
\hline 600 & 0.9317 & 0.9339 & 1.8656 \\
\hline 800 & 1.5006 & 1.0394 & 2.5400 \\
\hline 1000 & 2.7467 & 1.8246 & 4.5713 \\
\hline
\end{tabular}

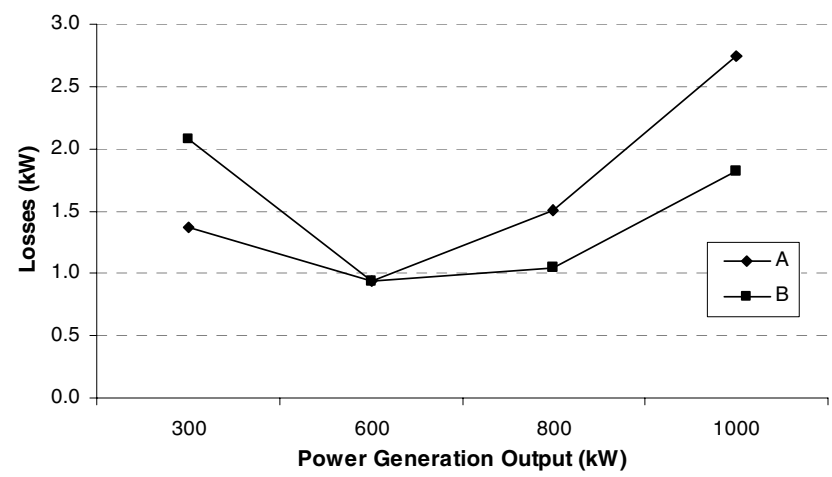

Fig. 3. Results of the loss re-allocation for the feeder in Fig. 1.

\section{CASE Study}

To evaluate the performance of the proposed methodology a medium voltage distribution network will be utilized. Two IEPs (DG units) will be installed in distant nodes in order to emphasize their impact on power losses. Initially, aimed at evaluating the influence of the generators, a number of scenarios varying their power output while keeping the same loading will be analyzed. Later, a given power generation output will be fixed and various loading scenarios analyzed. 
Results raise the discussion of whether the loss allocation problem should be utilized for specific demand-generation scenarios or should consider the time-varying characteristic of such parameters.

Medium voltage IEEE-34 test feeder [6] is shown in Fig. 4. The total single-line demand considered is $590 \mathrm{~kW}$, whereas $72 \%$ of the loads are located $56 \mathrm{~km}$ from the root node. The feeder has ACSR 1/0, 2 and 4 conductors. Transformer originally located between nodes 19 and 20 is substituted by a line section, i.e., the entire feeder is modeled at a single voltage level. Two DG units are inserted at nodes 30 and 33, which are distant from the substation and also close to the load concentration. Total power losses of the original network (without DG) are $165.97 \mathrm{~kW}$.

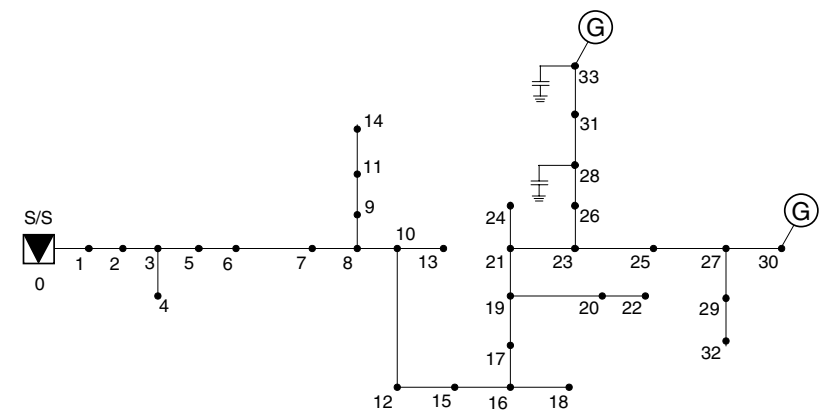

Fig. 4. Single-line IEEE-34 test feeder [6] with two DG units.

Table III shows the results of loss allocation considering the different power generation outputs. In the first scenario, each generator produces $30 \mathrm{~kW}$ (unity power factor), representing $10 \%$ of the total demand. Although the loads at nodes 30 and 33 represent $52 \%$ and $79 \%$, respectively, of the power generation, the impact on the total power losses is not negligible. Indeed, this scenario led to a reduction of $28 \%$ of total power losses, compared to the original configuration. Therefore, the adapted Zbus method allocated negative losses to the generation nodes 30 and 33, achieving $2.7 \%$ and $4.4 \%$ of the total power losses, respectively. The summation of these values represents the cross-subsidies that, in this case, the consumers would have to pay in excess. Thus, while the consumers may find reasonable to share the economic responsibility produced by $119 \mathrm{~kW}$ of total power losses, according to the adapted Zbus method, they should actually share the responsibility of $127 \mathrm{~kW}$, i.e. $7.1 \%$ more. This situation is overcome by the loss re-allocation method which eliminates the participation of the generation nodes and, while cross-subsidies still appear (nodes 1 and 2), the procedure leads to an expressive reduction of the total cross-subsidies: $0.12 \%$ of the total power losses.

An increase on the power generation output produces a larger reduction of the system's total power losses, as it can be verified when both generators are set to $200 \mathrm{~kW}$, supplying $67 \%$ of the feeder's total demand. In this case, the losses are still decreasing, i.e., the concept of "the larger the power generation output the smaller the network's total power losses" is still working, thus the consequent negative loss allocation to nodes 30 and 33 performed by the proposed Zbus method. The total cross-subsidies here accounts for $163.3 \%$ of the total power losses. Certainly, while this is a significant increase on the final bill of the consumers in terms of percentage, the economic implication will actually be much better than the previous generation scenario since the overall power losses decreased by $93 \%$ compared to the original configuration. Nonetheless, cross-subsidies still may represent a hassle and may not lead to an agreement of the participating agents. The application of the re-allocation method, in addition to eliminate the loss allocation to generation nodes, reduced significantly the cross-subsidies for this scenario. In fact, the summation of the negative losses now allocated to nodes $1,2,3$ and 4 accounts for $5.7 \%$ of the total power losses (28 times smaller than that computed by the adapted Zbus method).

TABLE III

RESULTS OF THE ADAPTED ZBUS ALLOCATION AND RE-ALLOCATION METHODS FOR THE IEEE-34 TEST FEEDER VARYING THE POWER GENERATION OUTPUT OF BOTH DG UNITS INSERTED AT NODES 30 AND 33

\begin{tabular}{c|c|c|c|c|c|c}
\hline \multirow{2}{*}{ Node } & \multicolumn{2}{|c|}{$\begin{array}{c}\text { Each DG unit 30 kW } \\
\text { Losses (kW) }\end{array}$} & \multicolumn{2}{c|}{$\begin{array}{c}\text { Each DG unit 200 kW } \\
\text { Losses (kW) }\end{array}$} & \multicolumn{2}{c}{$\begin{array}{c}\text { Each DG unit 300 kW } \\
\text { Losses (kW) }\end{array}$} \\
\cline { 2 - 7 } & Zbus & Re-alloc. & Zbus & Re-alloc. & Zbus & Re-alloc. \\
\hline 1 & 0.0314 & -0.0833 & 0.0108 & -0.2843 & 0.0022 & 0.2052 \\
\hline 2 & 0.0522 & -0.0627 & 0.0177 & -0.2776 & 0.0033 & 0.2064 \\
\hline 3 & 0.1311 & 0.0959 & 0.0411 & -0.0467 & 0.0045 & 0.0642 \\
\hline 4 & 0.1312 & 0.0960 & 0.0412 & -0.0466 & 0.0046 & 0.0643 \\
\hline 8 & 0.1174 & 0.1060 & 0.0333 & 0.0066 & 0.0013 & 0.0190 \\
\hline 9 & 0.8573 & 0.7759 & 0.2508 & 0.0601 & 0.0219 & 0.1482 \\
\hline 10 & 1.3512 & 1.2326 & 0.3823 & 0.1074 & 0.0204 & 0.2018 \\
\hline 11 & 4.5039 & 4.0977 & 1.4322 & 0.4830 & 0.2794 & 0.9078 \\
\hline 12 & 0.2964 & 0.2703 & 0.0828 & 0.0225 & 0.0029 & 0.0426 \\
\hline 13 & 1.1055 & 1.0085 & 0.3133 & 0.0887 & 0.0176 & 0.1658 \\
\hline 14 & 3.6227 & 3.2982 & 1.1638 & 0.4058 & 0.2418 & 0.7437 \\
\hline 15 & 3.1425 & 2.9022 & 0.8256 & 0.2803 & -0.0231 & 0.3338 \\
\hline 16 & 0.1359 & 0.1256 & 0.0355 & 0.0120 & -0.0013 & 0.0141 \\
\hline 18 & 0.1360 & 0.1256 & 0.0355 & 0.0120 & -0.0013 & 0.0142 \\
\hline 19 & 0.6236 & 0.5848 & 0.1485 & 0.0637 & -0.0189 & 0.0358 \\
\hline 21 & 2.0869 & 1.9591 & 0.4855 & 0.2072 & -0.0770 & 0.1022 \\
\hline 22 & 39.6814 & 37.3255 & 10.2771 & 5.1430 & -0.0049 & 3.3050 \\
\hline 23 & 7.6864 & 7.2221 & 1.7142 & 0.7079 & -0.3765 & 0.2706 \\
\hline 24 & 0.0779 & 0.0732 & 0.0189 & 0.0087 & -0.0018 & 0.0048 \\
\hline 25 & 15.2451 & 14.3353 & 3.4766 & 1.5073 & -0.6381 & 0.6277 \\
\hline 26 & 0.3896 & 0.3662 & 0.0875 & 0.0367 & -0.0182 & 0.0145 \\
\hline 27 & 5.2835 & 4.9657 & 1.1558 & 0.4685 & -0.2873 & 0.1543 \\
\hline 28 & 35.4166 & 33.1881 & 6.7917 & 1.9614 & -3.2471 & -0.1412 \\
\hline 29 & 1.2192 & 1.1456 & 0.2645 & 0.1054 & -0.0694 & 0.0328 \\
\hline 30 & -3.1599 & -- & -7.8650 & & 7.6078 & -- \\
\hline 31 & 2.9178 & 2.7412 & 0.6290 & 0.2469 & -0.1723 & 0.0733 \\
\hline 32 & 1.2197 & 1.1461 & 0.2647 & 0.1057 & -0.0691 & 0.0330 \\
\hline 33 & -5.2607 & -- & -10.7295 & & 4.4424 & -- \\
\hline Total & 119.0416 & 119.0416 & 11.3857 & 11.3857 & 7.6440 & 7.6440 \\
\hline & & & & & & \\
\hline
\end{tabular}

In the last case presented in Table III occurs what was commented in subsection 2.2: the generation exceeds the network's total demand and, consequently, the total losses exhibit an increasing trend. Here the adapted Zbus method allocates positive losses to the generation nodes pointing out their responsibility on the "increase" of network's power losses. Actually, the total power losses decreased by $95 \%$ compared to the original configuration, nonetheless, in this case where the demand is fully covered by DG various load nodes are allocated with negative losses. The total value of the cross-subsidies accounts for $65 \%$ of the network's total power losses. The re-allocation procedure made this value fall to $1.8 \%$.

Fig. 5 graphically expresses how the network's total real 


\section{Accepted Paper}

power losses decreased at each generation scenario. Moreover, a comparison between the adapted Zbus and Reallocation methods is presented in order to highlight how the final bill of those agents sharing the total loss allocation (summation of absolute values) will be affected. It is clear the need of minimizing cross-subsidies so proper market signals can be provided.

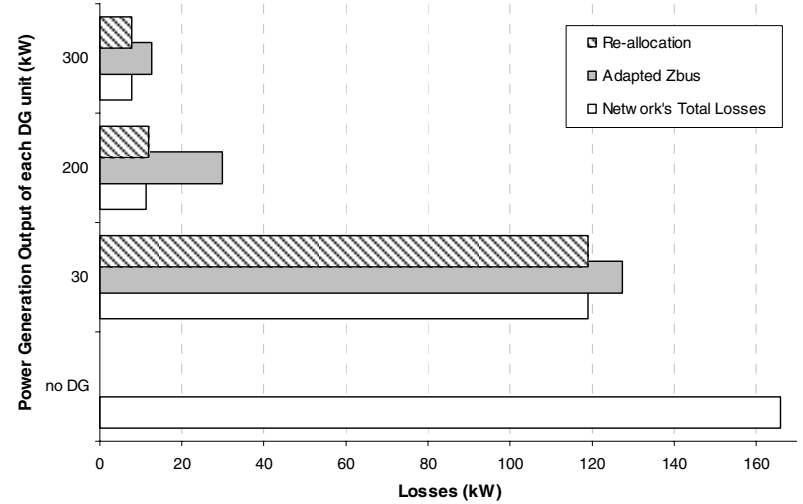

Fig. 5. Comparison of the total losses (summation of absolute values) allocated by the adapted Zbus and Re-allocation methods for the IEEE-34 test feeder varying the power generation output of both DG units inserted at nodes 30 and 33.

In order to observe the behavior of the loss allocation results obtained through the adapted Zbus method, results of generation nodes 30 and 33, as well as those of load nodes 11, 22 and 28 are plotted in Fig. 6, considering more power generation output scenarios.

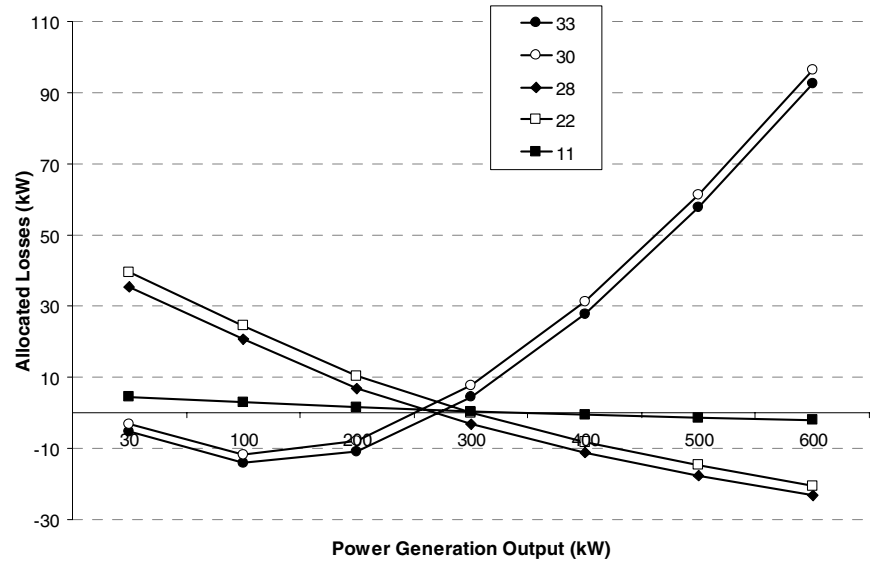

Fig. 6. Results of the adapted Zbus loss allocation method for the IEEE-34 test feeder varying the power generation output of both DG units inserted at nodes 30 and 33 .

It is verified that from $300 \mathrm{~kW}$ injected by each DG unit, the method solely allocates positive losses to the generation nodes. Nodes 28 and 22 represents the most loaded ones, whereas node 11 is the least loaded one. It can be verified that, although loss allocation depends on the loading and location of a given node, these three nodes exhibit decreasing trends when increasing the power generation output.

After applying the Re-allocation of losses, it is observed through Fig. 7 that the load nodes 11 and 22 follow the same trend of the total network's real power losses. The curve obtained by the addition of allocated losses to nodes 22 and 28 (their loading achieve $49.8 \%$ of the network's total demand) shows that they receive at all generation scenarios more than half of the total losses. This is coherent due to both the loading and location (load concentration) of both nodes.

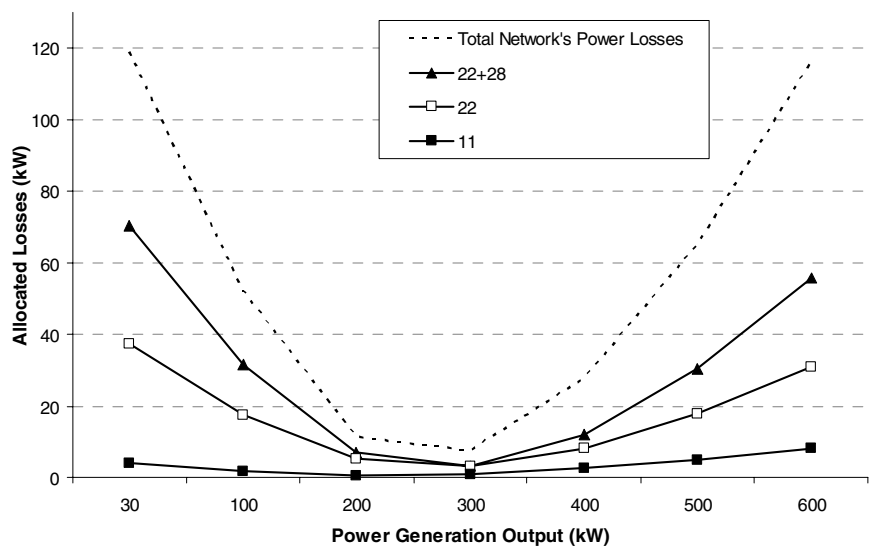

Fig. 7. Results of the Re-allocation method for the IEEE-34 test feeder varying the power generation output of both DG units inserted at nodes 30 and 33 .

TABLE IV

LOSS RE-ALLOCATION CONSIDERING DIFFERENT LOADING FOR THE IEEE-34 TEST NETWORK - DG AT NODES 30 E 33

\begin{tabular}{|c|c|c|c|}
\hline \multirow{2}{*}{ node } & Loading $10 \%$ & Loading $50 \%$ & Loading $120 \%$ \\
\hline & \multicolumn{3}{|c|}{ Loss Re-allocation (kW) } \\
\hline 1 & 0.1516 & -0.0679 & -0.4870 \\
\hline 2 & 0.1511 & -0.0663 & -0.4644 \\
\hline 3 & 0.0420 & -0.0110 & -0.0116 \\
\hline 4 & 0.0420 & -0.0110 & -0.0115 \\
\hline 8 & 0.0110 & 0.0016 & 0.0802 \\
\hline 9 & 0.0786 & 0.0143 & 0.5973 \\
\hline 10 & 0.1107 & 0.0254 & 0.9796 \\
\hline 11 & 0.3906 & 0.1142 & 3.3061 \\
\hline 12 & 0.0242 & 0.0053 & 0.2142 \\
\hline 13 & 0.0905 & 0.0210 & 0.8022 \\
\hline 14 & 0.3119 & 0.0959 & 2.6767 \\
\hline 15 & 0.2090 & 0.0657 & 2.4094 \\
\hline 16 & 0.0090 & 0.0028 & 0.1042 \\
\hline 18 & 0.0090 & 0.0028 & 0.1042 \\
\hline 19 & 0.0297 & 0.0148 & 0.5106 \\
\hline 21 & 0.0961 & 0.0481 & 1.7104 \\
\hline 22 & 1.7910 & 1.1882 & 33.6071 \\
\hline 23 & 0.3425 & 0.1645 & 6.2804 \\
\hline 24 & 0.0035 & 0.0020 & 0.0646 \\
\hline 25 & 0.6684 & 0.3507 & 12.5510 \\
\hline 26 & 0.0173 & 0.0085 & 0.3190 \\
\hline 27 & 0.2326 & 0.1089 & 4.3087 \\
\hline 28 & 1.6424 & 0.4511 & 27.8900 \\
\hline 29 & 0.0538 & 0.0245 & 0.9920 \\
\hline 30 & --- & --- & --- \\
\hline 31 & 0.1292 & 0.0574 & 2.3676 \\
\hline 32 & 0.0538 & 0.0246 & 0.9927 \\
\hline 33 & --- & --- & --- \\
\hline Total & 6.6917 & 2.6360 & 101.8937 \\
\hline
\end{tabular}

So far it has been shown the behavior of the process of loss re-allocation regarding a number of generation scenarios. However, it is important to observe that demand is also a time-varying parameter in power systems. Therefore, since power losses in transmission or distribution vary constantly, loss allocation methods should be used in such a manner that time intervals that characterize the demand (e.g. hourly analysis) are taken into account.

Considering a $100 \mathrm{~kW}$ power output for each generator connected at nodes 30 and 33, loss re-allocation will be 
evaluated assuming 10, 50 and $120 \%$ of the IEEE-34 network's loading adopted. Results are presented in Table IV.

Losses are certainly dependent on the connection points of the generation units given the effects that different DG arrangements may have on the system's total losses. Nonetheless, losses will also depend on the system's loading. Thus, for the most loaded node (22), re-allocation accounted for $26.8 \%$ of the total losses at the first scenario, which can be considered as "flat" loading in a load curve. At "medium" loading, re-allocation is $45.1 \%$ and at "peak" loading, accounts for $32.9 \%$. This variability is verified for all nodes, and occurs due to the non-linearities of losses.

\section{CONCLUSIONS}

Independent Energy Producers (Distributed Generation) and Independent Energy Consumers, as new agents of distribution systems that allow open access, may be widespread in the near future. In this scenario, where IEPs and IECs are able to negotiate energy contracts with agents outside the host distribution network, and considering current methodologies for calculating the sharing of losses, captive consumers will probably assume the whole responsibility of the system's losses.

In this work, a process for re-allocation of losses in distribution systems with open access was presented, aimed at minimizing cross-subsidies that appear as an effect of the generators over the system losses. Therefore, consumers (IECs and captive consumers) become the only responsible agents for the network losses, with no or minimal crosssubsidies.

The proposal considers the spatial characteristics of consumers in the distribution systems, being consistent, fair and easy to implement. Results obtained show the effectiveness in the minimization of cross-subsidies, which can be translated -to some extent- in more efficient and transparent economic signals of the market, making the proposal attractive as an option of loss allocation method in nowadays distribution systems with open access, and where DG is playing an increasing role.

\section{REFERENCES}

[1] A. J. Conejo, J. M. Arroyo, N. Alguacil, and A. L. Guijarro, "Transmission loss allocation: a comparison of different practical algorithms," IEEE Trans. on Power Systems, vol. 17, no. 3, pp. 571-576, Aug. 2002.

[2] J. Mutale, G. Strbac, C. S., and N. Jenkins, "Allocation of losses in distribution systems with embedded generation," IEE Proceedings Generation, Transmission \& Distribution, vol. 147, no. 1, pp. 7-14, Jan. 2000.

[3] I. F. E. D. Denis, "Métodos de alocação de perdas em sistemas de distribuição com geradores distribuídos," Ph.D. dissertation, Department of Electrical Engineering, UNESP - State University of Sao Paulo, Ilha Solteira, 2003.

[4] N. Zhao, Y. H. Song, and Z. H. Bie, "Improved Z-bus loss allocation method through redistribution," in Proc. 2004 Universities Power Engineering Conference-UPEC, vol. 3, pp. 1101-1105.

[5] A. J. Conejo, F. D. Galiana, and I. Kockar, "Z-bus loss allocation," IEEE Trans. on Power Systems, vol. 16, no. 1, pp. 105-110, Feb. 2001.
[6] W. H. Kersting, "Radial distribution test feeders," IEEE Trans. on Power Systems, vol. 6, no. 3, pp. 975-985, Aug. 1991.

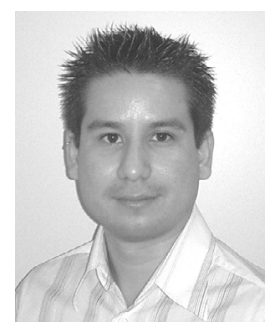

\section{BIOGRAPHIES}

Luis F. Ochoa (S'01, M'07) graduated from the National Engineering University (UNI) - Lima, Peru, in 2000. He obtained the M.Sc. and Ph.D. degrees from UNESP - Ilha Solteira, Brazil, in 2003 and 2006, respectively. He is also member of the Institution of Engineering and Technology (IET). His research interests are distribution system analysis and DG.

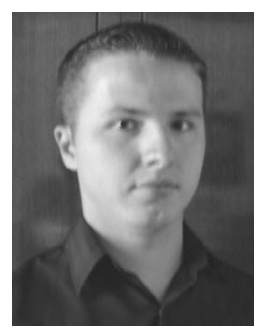

Marcelo Escobar de Oliveira (S'06) graduated from the State University of Sao Paulo (UNESP) Ilha Solteira, SP, Brazil, in 2004. Currently he is towards the Ph.D. at UNESP - Ilha Solteira, SP, Brazil. His research interests are distribution system analysis and distributed generation.

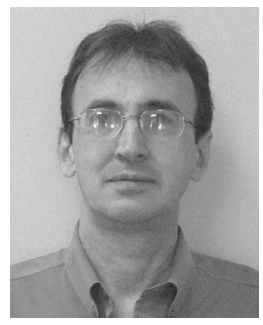

Antonio Padilha Feltrin (M'89, SM'06) obtained the B.Sc. degree from EFEI, the M.Sc. and $\mathrm{Ph} . \mathrm{D}$. from UNICAMP, Brazil. He is currently a Professor at UNESP - Ilha Solteira, SP, Brazil. From 1995 to 1997 he was a Visiting Faculty at ECE Department of University of Wisconsin - Madison. His main interests are in analysis and control of power systems. 